\title{
Culturas de ofício e práticas de cura na Lisboa moderna
}

\author{
Working cultures and treatment practices in \\ modern Lisbon
}

\author{
Lígia Bellini \\ Rua Irajá, 8 Parque Cruz Aguiar Rio Vermelho \\ 41940-630 Salvador - BA - Brasil \\ ligiabellini@uol.com.br
}

Santos, Georgina Silva dos.

Ofício e sangue: a Irmandade de São

Jorge e a Inquisição na Lisboa moderna.

Lisboa: Colibri; Portimão: Instituto de Cultura Ibero-

Atlântica, 2005. 315p.
$\mathrm{D}$ esde as últimas décadas do século passado, um número crescente de historiadores brasileiros tem se dedicado com grande competência a pesquisar temas de história de Portugal. Muitos deles foram movidos pelo objetivo de, por meio do entendimento de aspectos da história da metrópole, melhor compreender a América portuguesa, no que respeita à estrutura administrativa, às formas econômicas e sociais e a atitudes e imaginário. Outros, como é o caso da autora da obra aqui comentada, aparentemente foram motivados por um interesse mais direto por objetos relativos à história daquele país per se. Antes deste trabalho, a autora já havia desenvolvido outra pesquisa sobre história sociocultural portuguesa, sobre o papel da rainha na construção da identidade nacional, nos finais da época medieval e começos da moderna (Santos, 1995).

Ofício e sangue, originalmente tese de doutorado de Georgina Santos, apresentada em 2002 ao Programa de História Social da Universidade de São Paulo, trata aproximadamente do mesmo período e vai além, até o século XVIII, desta vez enfocando a Irmandade de São Jorge, que agregava mesteirais da corporação dos chamados ofícios de ferro e fogo. Estes incluíam desde atividades relativas ao atendimento curativo até a produção de armas brancas e de fogo, agregando barbeiros, armeiros, ferreiros, serralheiros e os que se dedicavam a ofícios afins.

A irmandade foi fundada em Lisboa em 1558 mas, no intuito de compreender a relação devocional dessa associação confraternal com o seu santo padroeiro, também padroeiro de Portugal desde o século XIV, a autora dedica o capítulo inicial do livro à análise das circunstâncias históricas nas quais emergiram diferentes representações de são Jorge e de como estas foram incorporadas ao imaginário político e religioso em Portugal. Inicialmente apropriado pela dinastia de Avis, em fins do século XIV, são Jorge passou à devoção popular na figura de protetor do reino. A adoção de tão 'celebérrimo' padroeiro é apontada como um fator que contribuiu para os privilégios que vieram a ter a bandeira e a irmandade.

Os capítulos seguintes são dedicados ao estudo das formas de associação e aos saberes dos homens da corporação de ferro e fogo, assim como aos regulamentos que incidiam sobre eles (capítulo II); e ao funcionamento interno da Irmandade de São Jorge, sua relação com a bandeira e sua atuação social (capítulo III). Neste último, destaca-se a discussão 
dos vínculos entre os irmãos de são Jorge e o Santo Ofício português. Entre os membros da irmandade, um grupo de irmãos eleitos pela Mesa participava das procissões e autos-de-fé da Inquisição, o que constitui evidência do seu status social e religioso. Os barbeiros de barbear, uma das profissões que integravam a 'cabeça' da bandeira, atuavam como 'sangradores dos cárceres', atendendo, junto com médicos e cirurgiões, aos encarcerados acometidos de moléstias, o mais das vezes causadas pelas condições insalubres do local ou decorrentes das penas e torturas a que eram submetidos. Além disso, o capítulo evidencia como, ao pautar a seleção de seus novos membros no cumprimento do paradigma de cristão propalado pelo Santo Ofício, principalmente no que dizia respeito à pureza de sangue, e ao ter um número crescente de associados que atuavam como familiares da Inquisição, a Irmandade de São Jorge contribuiu para acentuar a inserção e legitimação do Santo Ofício e de seu ideário no tecido social português.

De especial interesse para a história social da medicina portuguesa é o capítulo IV, intitulado "Mestres na arte de sangrar". Georgina Santos discute as trajetórias pelas quais o domínio da técnica de cura predominante na Idade Média e em boa parte da época moderna - a flebotomia -, uma atividade que se localizava na fronteira entre as artes mecânicas e as artes liberais, propiciou aos barbeiros, para além do ingresso nos quadros da Inquisição, a possibilidade de atuarem no Hospital Real de Todos os Santos. O hospital foi fundado por dom João II, cujo reino se estendeu de 1481 a 1495, e teve seu primeiro regulamento escrito em 1504. Com base nesse regulamento, em petições de indivíduos que desejavam trabalhar como flebotomistas no Hospital Real e no Santo Ofício, e em tratados sobre a arte de sangrar, a autora explora os tipos de cura oferecidos por barbeiros e cirurgiões, a rivalidade que se desenvolveu entre esses dois ofícios e outros aspectos do contexto médico da Lisboa moderna.

O capítulo apresenta um bem-informado quadro dos fundamentos do discurso médico para a sangria, argumentando com propriedade que, apesar da emergência, no século XVI, de novas abordagens e conhecimentos ligados à observação empírica, os pressupostos da medicina hipocrática e galênica continuaram dominando o pensamento médico até pelo menos o século XVII.

Boa parte do que é dito sobre a prática do tratamento médico fundase no Regulamento do Hospital Real de Todos os Santos. Aqui emerge o problema de ter-se que usar documentação regimental na tentativa de compreender práticas e relações sociais no passado, ainda mais num contexto caracterizado por uma considerável flexibilidade no que tange ao cumprimento de regulamentos. Isso é ilustrado pelas atividades profissionais e relações do médico espanhol Afonso Rodrigues de Guevara (datas não conhecidas) em Portugal, conquanto se trate de um indivíduo pertencente a um setor social distinto do abordado centralmente por Georgina Santos. Guevara, que havia estudado anatomia em Bolonha, era um conhecido professor de anatomia da Universidade de Valladolid quando o rei dom João III (1521-1557) o convidou para ministrar essa disciplina em Coimbra, como parte da reforma da universidade, empreendida pelo monarca. Guevara teve um encontro com 
o rei e a rainha em 1550. Segundo o que relata em seu livro (Guevara, 1559, dedicatória), ele dissecou o coração de um animal na presença do casal real, bem de acordo com o caráter espetacular que a prática da anatomia havia adquirido na época (ver Wilson, 1987). Guevara começou a ensinar em Coimbra em 1556, pouco antes da morte de dom João III. Sua amizade com a rainha Catarina lhe valeu muitos favores. Em 1557, uma cadeira de cirurgia foi criada na Universidade, para que ele a lecionasse junto com a de anatomia. Apesar de ter duas disciplinas a seu encargo, atas do conselho da Universidade indicam que ele se ausentava freqüentemente, para viajar para a corte em Lisboa e para a Espanha. Entre as dissecções anatômicas mencionadas em seu livro, incluindo anatomias em corpos humanos, Guevara apenas uma vez faz referência a dissecções praticadas em Coimbra durante o tempo em que ali esteve ensinando, e estas foram feitas em corpos de animais (Guevara, 1559, p.269).

Em 1561 Guevara mudou-se para Lisboa, sendo nomeado médico da rainha e do Hospital de Todos os Santos, no qual lhe foi confiada a tarefa de organizar o ensino de anatomia e de cirurgia. Apesar de conhecermos uma determinação obrigando-o a praticar anatomia no hospital, não há indicação, nas fontes, quanto ao cumprimento dessa ordem. Em resumo, tudo leva a crer que, apesar de ter sido um anatomista competente, potencialmente capaz de exercer uma importante influência no que concerne à anatomia e à observação empírica, Guevara pouco fez na universidade e no hospital. Sua participação nas atividades da corte e nos feitos militares parece ter sido mais intensa que sua performance como educador. Isso é sugerido pelo fato de que ele se encontrava entre os soldados e nobres aprisionados em Alcácer-Kebir (1578), onde a nata da nobreza portuguesa, incluindo o rei dom Sebastião (que reinou de 1568 a 1578), foi vencida e morta na tentativa frustrada de invadir o Marrocos (Lemos, 1899, v.1, p.221-223; Costa Santos, 1925, p.23ss.; Rocha Brito, 1937, p.56-62).

Ao trabalhar com fontes que permitem uma visão das falas, estratégias de inserção institucional e expectativas de barbeiros e cirurgiões, Georgina Santos preenche uma lacuna na história da medicina portuguesa, que enfatizou recorrentemente a dificuldade de se discutir os agentes associados à cura que não aqueles formados nas universidades, atribuindo essa dificuldade à estreita relação dos primeiros com um universo no qual predominava a oralidade. Porém, é relevante chamar atenção para o fato de que essas mesmas fontes - registros de solicitações de indivíduos que pleiteavam sua incorporação aos quadros da Irmandade de São Jorge, do Hospital de Todos os Santos e do Santo Ofício -, pela natureza dos critérios de ingresso nas instituições em questão, excluíam os que tinham qualquer ligação com sangue mouro, negro ou judeu. Se era prescrito por regulamento que a licença para o atendimento nas tendas, nos cárceres da Inquisição e no Hospital Real estava restrita apenas aos homens de sangue 'limpo', isso não significa necessariamente a ausência de praticantes médicos pertencentes às chamadas 'raças infectas', em especial judeus e mouros. Estudos e documentos indicam a importância destes no contexto médico português (ver Bellini, 1992, cap. 3; 2001, p.65-68). É bem verdade que 
focalizam o grupo letrado, mas neste também, por lei, devia haver restrições a mouros e judeus. A complexidade das interseções entre a medicina e os conflitos étnico-religiosos em Portugal é bem ilustrada numa passagem da alegoria sobre filosofia moral intitulada Ropicapnefma (1532), de João de Barros (1983), na qual a Vontade, um dos personagens do diálogo, que argumenta a favor dos valores seculares, pergunta ironicamente: "Qual foi o médico judeu ou mouro que não fosse a sua vista mais saudável a um cristão infermo que a dum triste e carregado confessor?" (Barros, 1983, v.II, p.28).

A presença de judeus no exercício da medicina em Portugal parece estar ligada à relação histórica mais geral desse grupo, tanto com a medicina letrada quanto com a prática médica junto à população como um todo. A grande incidência de médicos judeus em terras portuguesas, no século XVI, deve-se parcialmente à expulsão destes da Espanha, em 1492 (Jorge, 1914, p.19-20; Pina, 1952, p.398-399). No entanto, bem antes dessa data os reis lusitanos os empregavam, e no reino havia muitos deles, assim como cirurgiões judeus (Ferreira de Mira, 1947, p.50-52; Friedenwald, 1967, v.2, p.613-700, esp. p.691-694).

No domínio do saber letrado, no período que precedeu a atividade máxima da Inquisição, intelectuais judeus, oficialmente considerados cristãos-novos, mas que em certos casos preservavam secretamente seus costumes ancestrais, ocuparam posições de destaque na corte e na universidade. Por exemplo, os médicos Antonio Luiz (†1565) e Thomaz Rodrigues da Veiga (1513-1579) ensinaram na universidade, apesar de serem descendentes de famílias judias. Se a família de Veiga tinha muito tempo antes rompido com a fé hebraica, este não parece ter sido o caso da família de Antonio Luiz, cuja ascendência era conhecida na época (Silva Dias, 1969, v.1, p.229). Os médicos judeus Rodrigo de Castro (15461627) e Garcia Lopes (datas não conhecidas) eram objeto de grande estima por parte das elites políticas portuguesas (Lemos, 1899, v.1, p.257-259, 307). Dessa forma, pode-se dizer que a distinção usual entre doutores cristãos e judeus, com os últimos excluídos da universidade (ver Siraisi, 1990, p.58-59), não se aplica sem ressalvas a Portugal.

Mas tais questionamentos não implicam que Ofício e sangue perde valor como contribuição para a história da medicina, assim como para a história social, política e cultural portuguesa. É livro inteligente, que faz uso de documentação vasta, variada e original, que muito enriquece a bibliografia sobre essas diferentes áreas de estudo.

\section{REFERÊNCIAS BIBLIOGRÁFICAS}

Barros, João de

1983

Bellini, Lígia

2001

Bellini, Lígia

1992
Ropicapnefma (Lisboa, 1532). Reprodução fac-similada. Leitura modernizada, notas e estudo de Israel S. Revah. Lisboa: Instituto Nacional de Investigação Científica.

Medicina e saber erudito em Portugal no Renascimento. Estudos Ibero-Americanos, Porto Alegre, v.XXVII, n.1, p.43-74.

Representations of the human body in Sixteenth-Century Portugal. Tese (Doutorado) - University of Essex, Colchester. 
Costa Santos, Sebastião

$$
1925
$$

Ferreira de Mira, Matias

1947

Friedenwald, Harry 1967

Guevara, Afonso

Rodrigues de 1559

Jorge, Ricardo 1914-1916

Lemos, Maximiano 1899

Pina, Luis de 1952

Rocha Brito,

Alberto da

1937

Santos, Georgina Silva dos

1995

Silva Dias, José

Sebastião da 1969

Siraisi, Nancy G. 1990

Wilson, Luke 1987
O início da Escola de Cirurgia do Hospital Real de Todos os Santos, 1504-1565.

Lisboa: s.n.

História da medicina portuguesa.

Lisboa: Empresa Nacional de Publicidade.

The jews and medicine. Essays. New York: Ktav Publishing House; Baltimore: Johns Hopkins University Press.

In pluribus ex ijs quibus Galenus impugnatur ab Andrea Vesalio Bruxelési in cõstructione $\mathcal{E}$ usu partium corporis humani, defensio.

Coimbra: João de Barreira.

Comentos à vida, obra e época de Amato Lusitano. Arquivos de história da medicina portuguesa, Porto, Nova Série, 5ำ-ํㅜ anos, passim.

História da medicina em Portugal: doutrinas e instituições. Lisboa: Manoel Gomes.

Alguns aspectos históricos das relações médicas luso-espanholas. Revista de Las Ciencias, Madrid, ano XVIII, n.2, p.397-411.

A Faculdade de Medicina no século XVI.

Coimbra: s.n.

A Senhora do Paço: o papel da rainha na construção da identidade nacional portuguesa (1282-1557). Dissertação (Mestrado) - Universidade Federal Fluminense, Niterói (RJ).

A política cultural da época de D. João III.

Coimbra: s.n.

Medieval and early renaissance medicine.

Chicago: s.n.

William Harvey's prelectiones: the performance of the body in the renaissance Theater of Anatomy. Representations, Berkeley, v.17, p.62-95. 